\title{
Quantitative method to estimate species habitat use from light-based geolocation data
}

\author{
Jean-Baptiste Thiebot*, David Pinaud \\ Centre d'Etudes Biologiques de Chizé, CNRS UPR 1934, 79360 Villiers en Bois, France
}

\begin{abstract}
The development of biologging techniques has been instrumental in studying the behaviour of wild animals and interpreting it with respect to the bio-physical features of their habitat. Light-based geolocation currently appears to be the only technique suitable for the study of farranging small species, particularly marine species, over long periods, but it provides locations with low precision. In this study, we sought to improve the exploitation of these data. Specifically, the goals were to (1) correct rather than reject estimates, especially during equinox periods, (2) perform reproducible time-saving routine analyses, and (3) determine the spatial likelihood of the estimations to adapt inferences on habitat use by the population. We therefore applied an existing data-processing method based on spatial template fitting, using Markov Chain Monte Carlo and state-space modelling (Kalman filter) improved by a facultative sea surface temperature-matching procedure and a land mask. The main functions used for geolocation are grouped under the R package 'TripEstimation', freely available online. We focused on a typical example of animal movement that at present can only be ethically obtained from light-based geolocation. The method made it possible to estimate realistic positions during equinox periods and to routinely process the 12 available datasets. We thus obtained the most probable location for each sunrise/sunset as well as the posterior distribution around each estimated location, allowing an intuitive habitat use investigation at a scale of $100 \mathrm{~km}$. This paper describes the method used and provides the complete and comprehensively annotated commands required for its use.
\end{abstract}

KEY WORDS: Light-based geolocation $\cdot$ Habitat use $\cdot$ Method $\cdot$ Kalman filter $\cdot$ State-space model . Sea surface temperature $\cdot$ Large-scale movements

\section{INTRODUCTION}

The development of biologging techniques has brought considerable benefit to the challenge of studying the behaviour of wild animals, especially marine species, in their environment (e.g. Jouventin \& Weimerskirch 1990, Gunn et al. 1994, Wilson et al. 2002, Takahashi et al. 2004, Bailleul et al. 2007, Sato et al. 2007, Hays 2008). Among marine animals, pelagic seabirds have been a major subject in biologging studies (Jouventin \& Weimerskirch 1990, Wilson et al. 2002, Phillips et al. 2006, Pinaud \& Weimerskirch 2007). However, most of the tracking studies carried out on seabirds have taken place during their breeding period, when the animals are highly motivated to return to their colonies (Bost et al. 1997, Pinaud \& Weimerskirch 2007). Although the interbreeding period is known to be a critical phase for adult survival in many seabird species due to low prey availability (Croxall \& Davis 1999), our knowledge of their distribution during this period remains poor. The rare studies performed over this period have shown a distinct wintering strategy for pelagic seabirds (Wilson et al. 1998, Weimerskirch \& Wilson 2000, Croxall et al. 2005, Shaffer et al. 2006, Bost et al. 2009). Winter tracking is indeed challenging, due to the disturbance caused by conventional remote sensing units to the animal during a longer period (Wilson et al. 2002, Bost et al. 2004), and with respect to the demands of the technology (attachment, waterproofness, battery duration and 
memory capacity of the logger). This challenge increases in the case of diving species, as these highly streamlined animals are adapted to travel efficiently in a dense, viscous environment (Culik et al. 1994, Wilson et al. 2004). The development of ultra-miniaturised light-based geolocation loggers has therefore been a crucial step in tracking at-sea movements of diving species over long periods (Bost et al. 2009). The principle of the light-based geolocation technique is the calculation of a position from ambient light level readings with reference to time. The estimation of latitude is made from day (or night) length and longitude from the time of local midday (or midnight) relative to Greenwich Mean Time (GMT; Wilson et al. 1992, Hill 1994). Although this elegant method is convenient in many ways (small, antenna-free, inexpensive loggers), the precision of the estimated locations is not as high as that obtained from satellite transmitters (Musyl et al. 2001, Phillips et al. 2004, Nielsen et al. 2006, Nielsen \& Sibert 2007, Wilson et al. 2007, Lam et al. 2008). The main reason is that the calculation of latitude is unreliable for 2 to $3 \mathrm{wk}$ around each equinox, when day length is equivalent everywhere on Earth. In addition, light signals can be affected by several attenuation factors, including season, latitude, cloud cover, 'pollution' from artificial light sources, shading, changes in sensor orientation and behaviour of the studied animal, especially for diving species. Light-based estimations can subsequently be biased by other factors (distance travelled per day, clock drift). All of these factors thus limit the use of this technique (Wilson et al. 1992, Hill 1994, Teo et al. 2004, Ekstrom 2007).

Results obtained from biologging make ecological sense when put in the context of the studied phenomenon. For this reason, using habitat features at optimal scales is the key to understanding why animals behave as they do (Steele 1976, 1989, Haury et al. 1978, Hunt \& Schneider 1987, Kotliar \& Wiens 1990, Fauchald 1999, Fauchald et al. 2000, Bradshaw et al. 2002, Fritz et al. 2003, Pinaud \& Weimerskirch 2007, Galuardi et al. 2008). The exploitation of light-based geolocation data is particularly limited in ecology because of a lack of precise knowledge on their reliability. The main purpose of the present work was therefore to extract more from these light-based geolocation data.

Three objectives were specifically identified. First, improving location reliability with advanced analytic tools rather than simply rejecting unrealistic estimates, especially during equinox periods, was necessary so as to avoid information gaps on some parts of the trip. Second, since relatively high numbers of individuals are generally studied by light-level geolocation (see Croxall et al. 2005) due to its lower cost, data analysis is highly time-consuming. An automated data-processing method with consistent objective criteria would there- fore reduce the time needed, as well as improving reproducibility of the results among observers. Finally, determining spatial likelihood of geolocation estimates was vital to adapt to optimal scale inferences on habitat use by a population. Rather than developing a new tool, we based our work on the 'TripEstimation' package developed for the software R (R Development Core Team 2008). Other similar frameworks exist (e.g. Nielsen \& Sibert 2007, Lam et al. 2008), but this package is presently the only one available on the Comprehensive $\mathrm{R}$ Archive Network devoted to the estimation of animal movement from archival tags. All these methods share the same approach, involving state-space models. Patterson et al. (2008) defined this statistical approach as

A time-series model that predicts the future state of a system from its previous states probabilistically, via a process model. The [state-space] model describes mathematically how observations of the state of the system are generated via an observation model. (p. 87)

It is therefore possible to use the 'hidden state' of this process as a statistical correction to the observation information in order to infer the likelihood of an animal's position (e.g. Sibert \& Fournier 2001, Sibert et al. 2003, Jonsen et al. 2005, Patterson et al. 2008). We added to this statistical approach the step of sea surface temperature (SST) matching as suggested by Smith \& Goodman (1986) (see Delong et al. 1992, Hill 1994, Teo et al. 2004, Shaffer et al. 2005, Nielsen et al. 2006, Wilson et al. 2007). We focus on data obtained from a particularly relevant case study of light-based geolocation tracking. We describe the framework we applied, provide the R codes used with thorough annotations, show the stepwise progress in trip reconstitution and finally highlight the ecological exploitation of the model outputs.

\section{MATERIALS AND METHODS}

Study model and loggers used. Light-based geolocation data were obtained from the inter-breeding migration of 12 macaroni penguins Eudyptes chrysolophus from the Kerguelen Islands, southern Indian Ocean, in 2006 (see Bost et al. 2009). To track the penguins during their winter migration, we used MK9 Global Location Sensing (GLS) loggers manufactured by the British Antarctic Survey (Cambridge). A logger was fitted to one leg of each penguin using flexible leg bands specially designed by C. Bost (Centre National de la Recherche Scientifique, France). These loggers measure dim light level every minute and record the maximum value at the end of every $10 \mathrm{~min}$ period. In addition, ambient sea temperature is recorded with a resolution of $0.0625^{\circ} \mathrm{C}$ and an accuracy of $\pm 0.5^{\circ} \mathrm{C}$. As it takes $10 \mathrm{~min}$ for the temperature sensor reading to stabilise, the logger records tem- 
perature once during every 20 min period of continuous immersion. To conserve memory, another record is taken if there is a subsequent dry event followed by a further 20 min of continuous immersion. The number of records per day was therefore related to the number of bouts spent by the animal at the sea surface. Although one may expect that sensors attached to the leg of a penguin at sea would always be submerged and record water temperature at various depths, there is some factual knowledge that suggests the contrary. First, macaroni penguins perform dives with a mean depth of about $50 \mathrm{~m}$ in winter (Green et al. 2005), which is the layer depth of the pelagic ocean surface that usually demonstrates thermic homogeneity as a result of wind-induced mixing (Pickard \& Emery 1990, Park et al. 2008). Second, in macaroni penguins, the highest frequencies of maximum dive depth are reached for dives shallower than $10 \mathrm{~m}$ (Green et al. 2005, dives $<2.4 \mathrm{~m}$ removed). Finally, even if these animals are submerged about $60 \%$ of their at-sea time budget (Green et al. 2005), they are tightly linked to the surface for travelling, resting after diving, sleeping and preening (Wilson 1995). As a consequence, there are good chances to stabilise the temperature reading at the surface, and the logger may sometimes emerge, at least for brief moments. These small GLS loggers are increasingly being used to study a variety of species (Fox 2009), especially because of their low cost and mass. They weigh $6 \mathrm{~g}$ in the air, which corresponds to less than $0.14 \%$ of the mean penguin body mass (from Bost et al. 2009).

After logger recovery, we used the 'BAS Track' software provided by the British Antarctic Survey to decompress data from the logger into light and temperature files. This software also enables the corrrection of any clock drift in line with start and download times of the logger entered by the observer.

Light-based geolocation using the 'TripEstimation' package. The method presented is based primarily on the 'TripEstimation' package developed by M. Sumner \& S. Wotherspoon for the software R (R Development Core Team 2008) that we adapted to the file format provided by the 'BAS Track' extractor (see Supplement 1 at www.int-res.com/articles/suppl/n010p341_app/). This package provides estimation algorithms and a supporting code for light-based geolocation, which results in the estimation of 2 fixes $d^{-1}$, i.e. one at dawn and another at dusk. However, its application is somewhat confusing since it lacks sufficient help and examples. The R codes are therefore given in the supplement with thorough annotations; terms in inverted commas hereafter refer to $\mathrm{R}$ objects in these codes. First, some settings were needed before running the estimation (Table 1): maximum realistic spatial range for the trip, spatial resolution of the probabilistic calculation grid (Ekstrom template, see Ekstrom 2007), mean speed over 12 h, speed vari- ance, number of simulations, and light recording parameters that mostly depend on the logger specifications. Mean speed was set according to previous telemetric studies on a closely related species (Raya Rey et al. 2007), following a log-normal distribution, with speed variance equal to half mean speed, as recommended by the authors of the package. The date and time that delimited the calibration periods of the logger prior to deployment and after recovery at known locations were then specified. Calibration had to last several days (5 to $7 \mathrm{~d}$ is recommended by the manufacturer), and the precise calibration location had to be known. Using these calibration data, the 'mkCalibration' function of the package permitted the choice of some twilight segments for light calibration. Then, using date and time of start and end of the trip, light-level transition segments recorded during the whole trip were interactively selected. For datasets showing ill-defined light signals, this selection could be made manually by clicking on clear segments among those plotted (saved in the 'twindex' object). Datasets that were not noisy could be processed automatically using the rolling mean and variance functions of the 'fTrading' package. Both methods are given in the script provided in the supplement. Difference in light signal quality was assumed to be related to the behaviour of the species, e.g. if the legs were kept under the feathers, thereby shading the light sensor. The geolocation model could afterwards be run using the 'solar.model' function in the package. This model is a state-space model including the specific behavioural and probabilistic parameters previously tuned. State-space models, consisting of a state and of an observation equation, are generally used to estimate the state of the system through the observation equation, over a discrete time scale. These estimations are based on incomplete observations and assume a perfect knowledge of the behaviour of the system (i.e. of the parameters of the state equation), while the observation equation relates this state to measurements of the system (Harvey 1989), here the light signals. In the simplest case of a linear statespace model, the Kalman filter (Kalman 1960) provides a method for recursively forecasting the values of the state vector from the past observations (see Brillinger 1981, Sibert \& Fournier 2001, Sibert et al. 2003, Jonsen et al. 2005, Royer et al. 2005, Nielsen \& Sibert 2007, Patterson et al. 2008, Lam et al. 2008, Véran \& Lebreton 2008 for applications). The interest of Kalman filtering in our case is that it can build a likelihood of the data to realise the estimates, and therefore furnish a probabilistic approach to an animal's location. In doing so, one attempts to investigate process (the location) based on patterns (light levels and time), but this may result in many possible solutions and thus low relevance of the estimates. For this reason this likelihood is combined later with other information (land, SST). 
Table 1. Synthesis of the geolocation process: sources, chronology, objects (code, meaning, value) and outputs. SST: sea surface temperature; GMT: Greenwich Mean Time; MCMC: Markov Chain Monte Carlo; POET website: http://poet.jpl.nasa.gov/

\begin{tabular}{|c|c|c|}
\hline Code in the R script & Description & Value/format \\
\hline $\begin{array}{l}\text { Sources and settings } \\
\text { lig; temp }\end{array}$ & $\begin{array}{l}\text { Light/time and temperature/time data files, obtained from } \\
\text { 'BAS Track' extractor }\end{array}$ &. $\operatorname{lig} ;$.tem \\
\hline $\begin{array}{l}\text { lon.min; lon.max; } \\
\text { lat.min; lat.max }\end{array}$ & $\begin{array}{l}\text { Longitude }\left({ }^{\circ} \mathrm{E}\right) \text { and latitude }\left({ }^{\circ} \mathrm{N}\right) \text { coordinates of the realistic } \\
\text { spatial range of the tracked animal }\end{array}$ & $20 ; 135 ;-70 ;-35$ \\
\hline$x x ; y y$ & Spatial resolution of the probabilistic calculation grid & $0.5^{\circ}$ \\
\hline low.d; high.d & Date and time of the start and end of the trip & \\
\hline bathyfile & $\begin{array}{l}\text { Name and path of the bathymetry file that will be used as a } \\
\text { land mask }\end{array}$ & .asc \\
\hline $\begin{array}{l}\text { seuil.low; seuil.high; } \\
\text { ecart }\end{array}$ & $\begin{array}{l}\text { Range of acceptable temperatures recorded to remove aberrant } \\
\text { values (low and high thresholds), and tolerance window around } \\
\text { the recorded value to realise the SST matching }\end{array}$ & $-1^{\circ} \mathrm{C}_{i} 15^{\circ} \mathrm{C}_{i} 2^{\circ} \mathrm{C}$ \\
\hline filemaster; dossier & $\begin{array}{l}\text { Number associated with the request made on the POET website } \\
\text { to download SST files, and path to the folder where the SST } \\
\text { files were downloaded }\end{array}$ & 7241 \\
\hline $\begin{array}{l}\text { d1pre } C_{i} \text { d2pre } C_{i} \\
\text { d1post } C_{;} \text {d2postC }\end{array}$ & $\begin{array}{l}\text { GMT dates and times of start/end of the calibration periods } \\
\text { (before deployment and after recovery) }\end{array}$ & yyyy-mm-dd hh:mm:ss \\
\hline pos.preC; pos.postC & $\begin{array}{l}\text { Location where calibrations were made }\left({ }^{\circ} \mathrm{E} \text { longitude, }{ }^{\circ} \mathrm{N} \text { latitude }\right. \\
\text { in decimal degrees) }\end{array}$ & $\begin{array}{l}(70.30,-49.06) ;(70.184 \\
-49.360)\end{array}$ \\
\hline $\begin{array}{l}\text { speed.mu; speed.sigma; } \\
\text { behav.dist }\end{array}$ & Mean speed over $12 \mathrm{~h}$ time, variance and distribution & $\begin{array}{l}2 \mathrm{~km} \mathrm{~h}^{-1} ; 1 \mathrm{~km} \mathrm{~h}^{-1}, \log - \\
\text { normal }\end{array}$ \\
\hline $\begin{array}{l}\text { light.sigma; } \text { k.sigma; } \\
\text { ekstrom }\end{array}$ & $\begin{array}{l}\text { Light recording parameters: variance in light data, variance for } \\
\text { light attenuation, and parameters to use for Ekstrom algorithm } \\
\text { limits (minimal and maximal solar elevation, and sigma for } \\
\text { outside that range) }\end{array}$ & $7 ; 10 ;(-10,8,7)$ \\
\hline nsim & Number of simulations & 1000 (default value) \\
\hline \multicolumn{3}{|c|}{ Calibration and segment definitions } \\
\hline calib & $\begin{array}{l}\text { Calibration of the light signals using data from } 1 \text { of the } \\
2 \text { calibration periods }\end{array}$ & $\begin{array}{l}\text { Enter indices of the } \\
\text { segments to be used }\end{array}$ \\
\hline twindex & $\begin{array}{l}\text { Light segments (dawn and dusk) selected by clicking or } \\
\text { automatically - see 'Materials and methods' for details }\end{array}$ & \\
\hline \multicolumn{3}{|c|}{ Model preparation: construction and application of the masks } \\
\hline \multicolumn{3}{|l|}{ Model running } \\
\hline d.model & $\begin{array}{l}\text { Light-based geolocation model with all supplementary } \\
\text { constraints (spatial range, travelling behaviour, land, SST) }\end{array}$ & \\
\hline plg & Locations that satisfy the masks for each light segment & \\
\hline$c h$ & Locations of maximum likelihood after running MCMC simulations & \\
\hline $\begin{array}{l}\text { Model outputs } \\
\text { ch }\end{array}$ & $\begin{array}{l}\text { Model outputs: chains of estimates, maximum likelihood } \\
\text { estimates, summary of the functions and parameters used }\end{array}$ & R data \\
\hline finLoc & File containing maximum likelihood locations at each time step & .txt \\
\hline cilong & $95 \%$ confidence interval for each location & \\
\hline$f f z$ & Grid of density estimates in each cell & \\
\hline spix & Cell size of the $f f z$ grid & $0.1^{\circ}$ \\
\hline (map) & Map of the most probable track over all the trip estimations & Graphic \\
\hline
\end{tabular}


In order to initialise the estimation, some starting points that satisfy the land and SST masks had to be found: the light level likelihood was evaluated across the grid, and the maximum was saved for each twilight segment as the 'plg' object. An initialisation version of the 'metropolis' sampler was then used to find valid locations for the starting point of the trip. This function provides a direct implementation of the MetropolisHastings algorithm (Metropolis et al. 1953, Hastings 1970), to run location estimates using Markov Chain Monte Carlo (MCMC). MCMC is a Bayesian simulation approach which enables the user to make inferences about unknown states and parameters of the model by simulating values of the states and parameters conditional on previously generated values until the chain of samples converges to the posterior distribution (see Geman \& Geman 1984, Gilks et al. 1996, Patterson et al. 2008, Sumner et al. 2009). Finally, the estimation model runs over the simulations, and the maximum likelihood estimates are saved for each simulation in the 'ch' object.

Improvement of the estimations using temperature data. To reduce the spatial range of possible locations, especially during equinox periods, we used the temperature recorded by the loggers as a supplementary spatial constraint in the model. Basically, we developed a matching procedure between logger SST records and a surrounding SST map. We integrated this facultative procedure in the same geolocation model with the aim of producing locations only once, in a parsimonious approach (i.e. not as an independent filter applied successively). As lightbased longitude estimates are more accurate and robust than light-based latitude estimates (Gunn et al. 1994, Musyl et al. 2001, Phillips et al. 2004, Teo et al. 2004), we used this supplementary constraint to re-estimate latitude. This is the general use of SST in temperate regions, since on a large scale, the surface of open oceans is structured in an SST gradient, with SSTs becoming cooler towards the poles. This global feature permits the location of the latitude of any individual temperature record in a given large-scale situation in a hemisphere (see Shaffer et al. 2005). The southern Indian Ocean presents a strong latitudinal SST gradient on its surface (Holliday \& Read 1998), which is a good opportunity to use the logger temperature records to adjust the latitude estimations. We used weekly averaged Reynolds satellite SST data with $1^{\circ}$ resolution (Reynolds \& Smith 1994) as a template, downloaded from the POET-PODAAC website (http://poet.jpl.nasa. gov/). The temporal resolution chosen was a compromise: on the one hand, a short-time range is a better indicator of local conditions to best correct the 2 daily fixes; on the other hand, meso-scale oceanographic activity in this region produces a non-linear variation of SST along latitude, which had to be smoothed according to the meso-scale structures velocity (Swart et al. 2008). Spatial resolution was also chosen according to the necessity to merge meso-scale oceanographic activity, which adds strong heterogeneity at scales of $100 \mathrm{~km}$ (Swart et al. 2008). Data preparation for this additional step consisted in removing unrealistic values, since trying to improve light-based geolocation estimates without relevant supplementary information is nonsensical. Temperature records by the loggers of more than $15^{\circ} \mathrm{C}$ and less than $-1^{\circ} \mathrm{C}$ were considered anomalous for the region delimited (Holliday \& Read 1998) and were therefore removed. Moreover, 1 matching parameter ('ecart') had to be adjusted. This value represents the tolerance window around the recorded value needed to realise the SST match. Each weekly averaged SST map acted as a mask, derived from the records made during the corresponding week, to constrain the light-based latitude estimates. These SST maps were called successively in a loop, using the numbers generated chronologically when they were downloaded from POET-PODAAC (ftp://podaac.jpl.nasa.gov/tmp/esip/). To assess the importance of the 'ecart' parameter on latitude estimates, we conducted the process using 7 different 'ecart' values: $0.1,0.2,0.5,1,2,3$ and $5^{\circ} \mathrm{C}$. Finally, it is noteworthy that this SST-matching procedure could be bypassed if temperature records were not available and the subsequent steps could be performed, regardless.

Confidence envelope of the reconstituted trip. Improving geolocation estimates but also determining their error distributions are main goals in the field of electronic tagging (Gunn \& Block 2001). The iterative method proposed in the 'TripEstimation' package produces 1000 location estimations for each light-level transition. All of these estimations are saved in the 'ch' object and plotted together. This plot is useful to reveal the posterior distribution for each transition, as a longitudinal and latitudinal range of possible locations of the animal along its trip. A more interesting application in ecology is to plot the number of estimations obtained per spatial unit (i.e. the local density of estimations: 'ffz'), which reflects a useful proxy of the probability that a location falls in a cell of the grid. This is possible at the scale of a single trip; however, the major interest of this proxy should appear at the population level, when density grids obtained for several simultaneous trips of individuals are mapped and added. Such a superimposed map may reveal spatial strategies, with areas most frequently used being highlighted. This is a major ecological outcome of this method, and is simple to perform by saving all the outputs in the same grid. 


\section{RESULTS}

The 12 available data sets were processed using this method. Logger temperature records contained $2.19 \pm$ $2.33 \%$ (mean \pm SD of the 12 datasets) of unreasonable values, this ratio representing up to $7.4 \%$ for 1 logger. In particular, many records of $127^{\circ} \mathrm{C}$ were found. The results of the estimation of the winter migration of 1 ind., using different constraints, are detailed in Fig. 1. The trip estimation obtained from light signals with range, start/end point, speed and land mask constraints resulted in unrealistic local movement patterns, especially close to the island and at the maximum range locations, where the animal was during the equinox periods (see also Fig. 2a). Processing the Kalman filter resulted in a trip with a smoothed appearance, particularly noticeable for equinox periods (see Fig. 1). Finally, the use of SST records as an additional and concomitant constraint in the model led to a substantial reduction of the latitudinal range. Mean speed, time at sea, maximum range and total distance travelled by the penguins were calculated for the estimated winter trips of 12 ind. and appear in Table 2. The location estimations given by each iteration of the model were saved and the posterior distribution for both longitude and latitude for 1 ind. along its trip was drawn (Fig. 2a,b, respectively; same individual as shown in Fig. 1). This allowed us to calculate for each point the longitudinal and latitudinal range of possible locations of an animal along its trip (Fig. 2c). Mean \pm
SD values among 12 ind. (see Table 3 ) were $1.53 \pm 0.37$ decimal degrees in longitude and $1.01 \pm 0.37^{\circ}$ in latitude (114 \pm 28 and $113 \pm 41 \mathrm{~km}$, respectively), with a mean maximum of $2.65^{\circ}(197 \mathrm{~km})$ in longitude and $1.76^{\circ}(196 \mathrm{~km})$ in latitude. Mean longitudinal and latitudinal width were not significantly different (Welch 2sample $t$-test, $t=0.3348$, $\mathrm{df}=12.919, \mathrm{p}=0.7431$ ); however, the mean SD of latitudinal width was significantly higher than that of the longitudinal width (Welch 2-sample $t$-test, $t=-7.0264$, df $=21.502, \mathrm{p}=$ $5.4\left(0^{-7}\right)$. Longitudinal and latitudinal width for a same individual were not correlated (Pearson's productmoment correlation, $t=0.3164, \mathrm{df}=10, \mathrm{p}=0.7582$ ).

The 7 series of results obtained using different 'ecart' values led to contrasted latitude estimate patterns (Table 4, Fig. 3). Note that lower values gave more uneven patterns, but with comparable latitude estimates during dispersion and return migrations. Conversely, higher values gave more smooth patterns, with a tendency to separate both migrations: eastward movement (dispersion) was estimated more southerly, and westward movement (return) more northerly. According to these results, an 'ecart' value of $2{ }^{\circ} \mathrm{C}$ seemed in this case the best compromise between a smoothed trip pattern and realistic locations.

Finally, the local density of estimations by sector could be drawn on a map for this individual along its entire winter trip (Fig. 4a). Superimposing the densities obtained for all individuals resulted in a map accentuating hotspots of habitat use by the population (Fig. 4b).

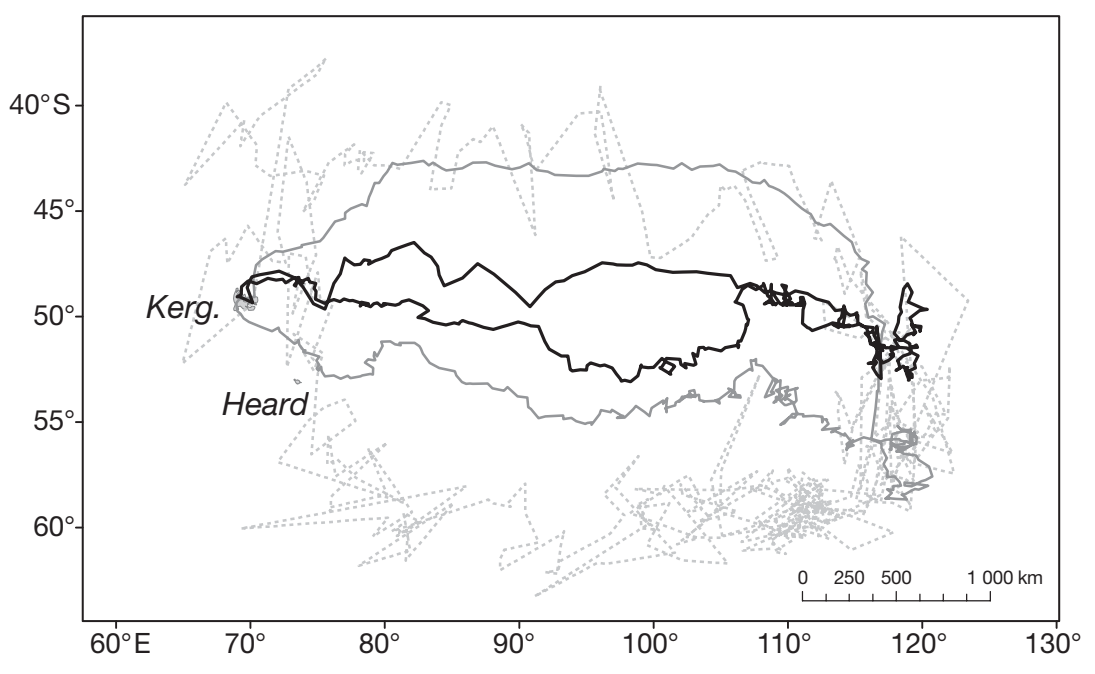

Fig. 1. Eudyptes chrysolophus. Example of a winter trip of 1 macaroni penguin from the Kerguelen Islands ('Kerg.') estimated using additive constraints: 1: light-based estimates using range, start and end point, speed and land mask constraints (dashed line); 2: most probable track using Kalman filter and previous constraints (thin solid, grey line); 3 : most probable track using all previous constraints and latitude adjustment by sea surface temperature (SST) matching (solid, black line). Heard: Heard Island

\section{DISCUSSION}

The method presented here allowed us to analyse 12 datasets of light signals obtained from a flightless, swimming seabird, the macaroni penguin. Ecological aspects of these results are discussed by Bost et al. (2009). Regarding the method, the objective was to make better use of light-based geolocation data obtained over extensive periods, by a template-fit probabilistic approach combining several spatial grids of information. A similar approach was proposed by Nielsen \& Sibert (2007) and Lam et al. (2008), albeit using a different statistical framework. We do not claim that the method we used is better, but rather show that this existing tool is also suited for light-based geolocation. We hope that the $\mathrm{R}$ codes we append here with explanations will encourage others involved in this research area to 

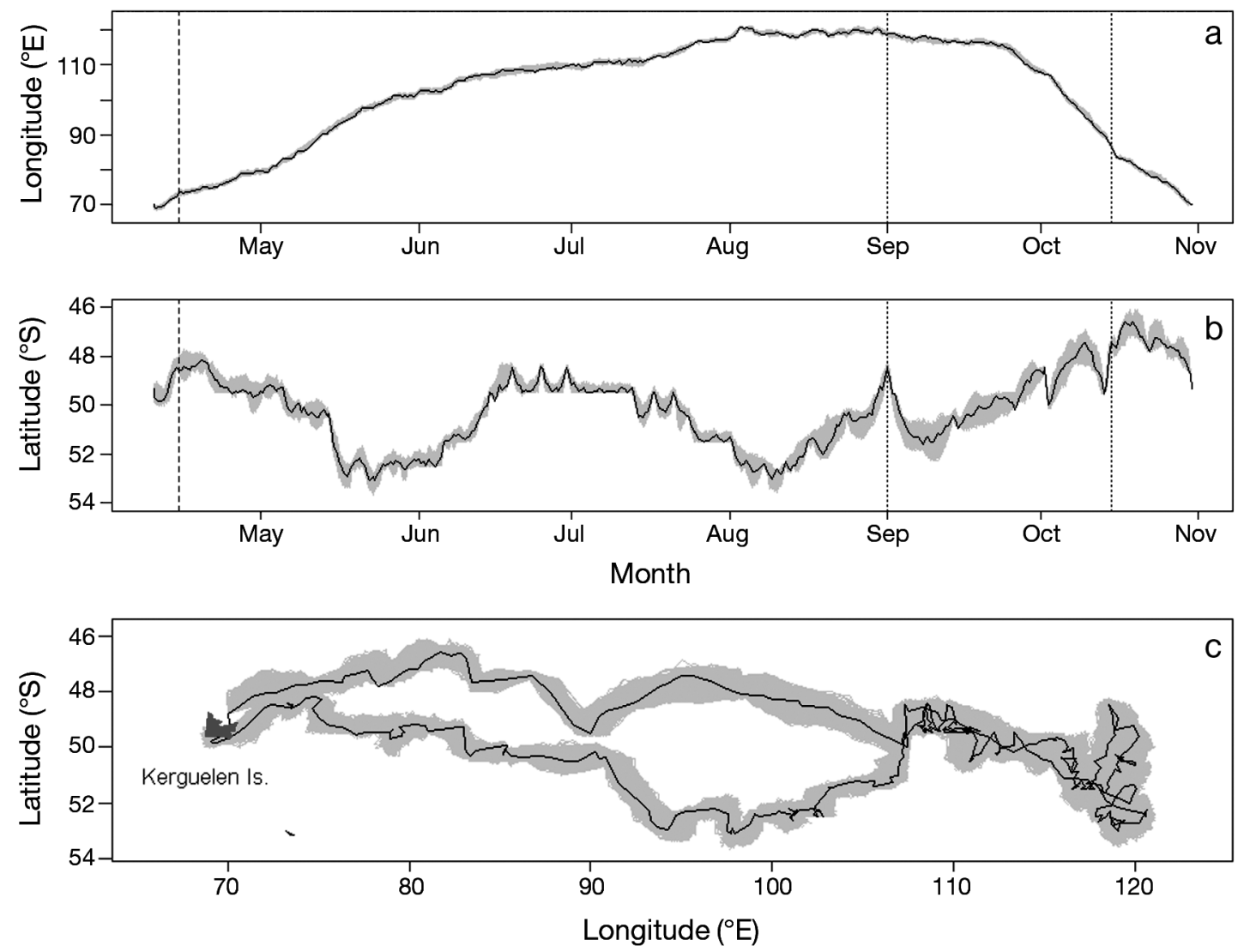

Fig. 2. Most probable estimations of longitude (a) and latitude (b) along the trip (black line), surrounded by all the estimations provided by the model (grey area). Vertical lines delimit 3 wk around equinoxes of spring (dashed) and fall (dotted). (c) Most probable trip plotted in longitude and latitude (black line) over all the trip estimations (grey area)

try this approach, especially those who deploy loggers similar to ours. An innovative aspect of our method is the use of an MCMC Bayesian simulation approach to estimate unknown states and parameters of the model.
Useful outcomes of this approach also encompass the direct ecological inference made possible from the local density of estimates (see also Nielsen \& Sibert 2007, Lam et al. 2008).
Table 2. Eudyptes chrysolophus. Mean speed, time at sea, maximal range and total distance travelled calculated from the estimated trip for $\mathrm{n}=12$ ind.

\begin{tabular}{|lcccc|}
\hline $\begin{array}{l}\text { Individual } \\
\text { no. }\end{array}$ & $\begin{array}{c}\text { Mean speed } \\
\left(\mathrm{km} \mathrm{h}^{-1}\right)\end{array}$ & $\begin{array}{c}\text { Time at } \\
\text { sea }(\mathrm{d})^{\mathrm{a}}\end{array}$ & $\begin{array}{c}\text { Maximal } \\
\text { range }(\mathrm{km})^{\mathrm{a}}\end{array}$ & $\begin{array}{c}\text { Total distance } \\
\text { travelled }(\mathrm{km})^{\mathrm{a}}\end{array}$ \\
\hline 1039 & 2.21 & 160 & 2868 & 10518 \\
1065 & 1.96 & 169 & 2013 & 10885 \\
1067 & 2.62 & 181 & 3680 & 13434 \\
1339 & 2.19 & 201 & 3143 & 10834 \\
1340 & 2.05 & 192 & 2158 & 9481 \\
1343 & 1.98 & 200 & 1846 & 9681 \\
1344 & 1.99 & 194 & 1460 & 9504 \\
1345 & 2.39 & 204 & 3561 & 11907 \\
1347 & 2.29 & 191 & 3443 & 10563 \\
1349 & 2.09 & 201 & 3030 & 10263 \\
1350 & 1.93 & 187 & 812 & 8739 \\
1351 & 1.95 & 197 & 977 & 9354 \\
${ }^{\mathrm{a} D a t a}$ from Bost et al. $(2009)$ & & & \\
\hline
\end{tabular}

\section{Production of realistic-only locations: a conservative approach}

Our early concern about rejecting unrealistic estimates has been overcome. With the use of likelihoods derived from a combination of several sets of information (including light levels, the animal's travelling behaviour, and land and SST masks) reducing the field of corresponding locations, no unrealistic position was produced. This is therefore a conservative approach, with no removal of any location estimate (see also Nielsen \& Sibert 2007, Lam et al. 2008). Equinox periods and diving behaviour of the 
Table 3. Eudyptes chrysolophus. Mean \pm SD and maximal width (decimal degrees; $\mathrm{km}$ ) of the posterior distribution for latitude and longitude of the trips for $\mathrm{n}=12$ ind.

\begin{tabular}{|c|c|c|c|c|c|c|}
\hline \multirow{2}{*}{ Individual } & \multicolumn{3}{|c|}{ Longitude $^{\circ} ; \mathrm{km}$} & \multirow{2}{*}{ Mean width } & \multicolumn{2}{|c|}{ atitude $^{\circ} ; \mathrm{km}$} \\
\hline & Mean width & $\mathrm{SD}$ & Maximal width & & $\mathrm{SD}$ & Maximal width \\
\hline 1039 & $1.50 ; 112$ & $0.32 ; 24$ & $2.11 ; 157$ & $1.01 ; 112$ & $0.38 ; 42$ & $1.86 ; 207$ \\
\hline 1065 & $1.59 ; 118$ & $0.45 ; 33$ & $3.40 ; 253$ & $1.08 ; 120$ & $0.34 ; 38$ & $1.69 ; 188$ \\
\hline 1067 & $1.52 ; 113$ & $0.33 ; 25$ & $2.01 ; 150$ & $1.11 ; 123$ & $0.36 ; 40$ & $1.71 ; 190$ \\
\hline 1339 & $1.53 ; 114$ & $0.37 ; 28$ & $2.79 ; 208$ & $1.02 ; 113$ & $0.33 ; 37$ & $1.57 ; 175$ \\
\hline 1340 & $1.57 ; 117$ & $0.34 ; 25$ & $2.55 ; 190$ & $0.98 ; 109$ & $0.39 ; 43$ & $1.87 ; 208$ \\
\hline 1343 & $1.46 ; 109$ & $0.28 ; 21$ & $1.86 ; 138$ & $0.96 ; 107$ & $0.41 ; 46$ & $1.92 ; 213$ \\
\hline 1344 & $1.49 ; 111$ & $0.32 ; 24$ & $2.22 ; 165$ & $1.05 ; 117$ & $0.34 ; 38$ & $1.79 ; 199$ \\
\hline 1345 & $1.58 ; 117$ & $0.42 ; 31$ & $3.29 ; 245$ & $0.82 ; 91$ & $0.38 ; 42$ & $1.81 ; 201$ \\
\hline 1347 & $1.56 ; 116$ & $0.47 ; 35$ & $3.30 ; 246$ & $1.13 ; 126$ & $0.42 ; 47$ & $1.90 ; 211$ \\
\hline 1349 & $1.46 ; 109$ & $0.35 ; 26$ & $2.45 ; 182$ & $1.02 ; 113$ & $0.36 ; 40$ & $1.62 ; 180$ \\
\hline 1350 & $1.58 ; 117$ & $0.35 ; 26$ & $2.38 ; 177$ & $1.12 ; 125$ & $0.39 ; 43$ & $1.84 ; 205$ \\
\hline 1351 & $1.52 ; 113$ & $0.48 ; 36$ & $3.45 ; 257$ & $0.87 ; 97$ & $0.29 ; 32$ & $1.54 ; 171$ \\
\hline
\end{tabular}

Table 4. Mean $\pm \mathrm{SD}$ of latitudinal range of the estimates along 1 entire track for 7 values of the 'ecart' parameter

\begin{tabular}{|lccc|}
\hline 'ecart' value $\left({ }^{\circ} \mathrm{C}\right)$ & Mean $\left({ }^{\circ}\right)$ & $\mathrm{SD}\left({ }^{\circ}\right)$ & Maximum $\left({ }^{\circ}\right)$ \\
\hline 0.1 & 0.22 & 0.24 & 0.87 \\
0.2 & 0.29 & 0.25 & 0.91 \\
0.5 & 0.46 & 0.27 & 1.35 \\
1 & 0.62 & 0.30 & 1.54 \\
2 & 0.82 & 0.38 & 1.81 \\
3 & 1.02 & 0.37 & 2.03 \\
5 & 1.25 & 0.26 & 1.98 \\
\hline
\end{tabular}

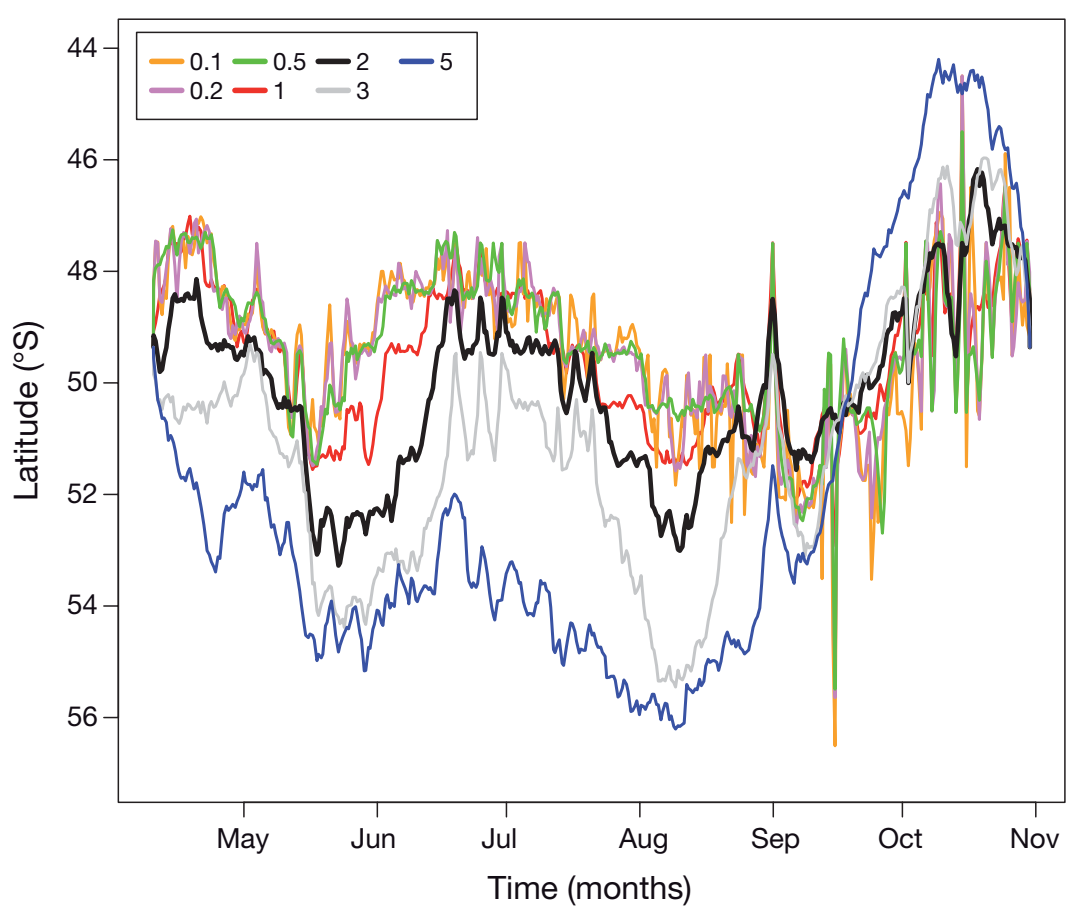

Fig. 3. Maximum likelihood latitude estimates along 1 track for 7 values of the 'ecart' parameter studied species proved not to be insurpassable obstacles for light-based geolocation when our framework was applied. Features of the loggers we used also enabled us to avoid the problem of light attenuation due to diving behaviour, since light records retained were the maximum value measured by the loggers over $10 \mathrm{~min}$, and the mean dive duration of the macaroni penguin is around $140 \mathrm{~s}$ during winter (Green et al. 2005). In the case of a non-air-breathing species, or animals performing very long and deep dives, diving behaviour may be the source of increased light-based geolocation difficulties. However, other methods have already shown that it is possible to overcome this issue (e.g. Sibert et al. 2003, Teo et al. 2004, Field et al. 2005, Lam et al. 2008).

\section{Reproducible and time-saving process}

Thanks to the lower cost of the loggers in a light-based geolocation study, numerous datasets are generally available (see Croxall et al. 2005). Thus, the time required to analyse these datasets can be an issue. The process followed here has been shown to be time-saving when there are numerous datasets to analyse. There are 2 basic reasons for this time gain. First, once parameters are set and calibration segments are chosen, little or no intervention is needed, thus allowing several datasets to run simultaneously, or successively in routine. Second, this process does not require visual inspection of each trip obtained to reject unrealistic esti- 

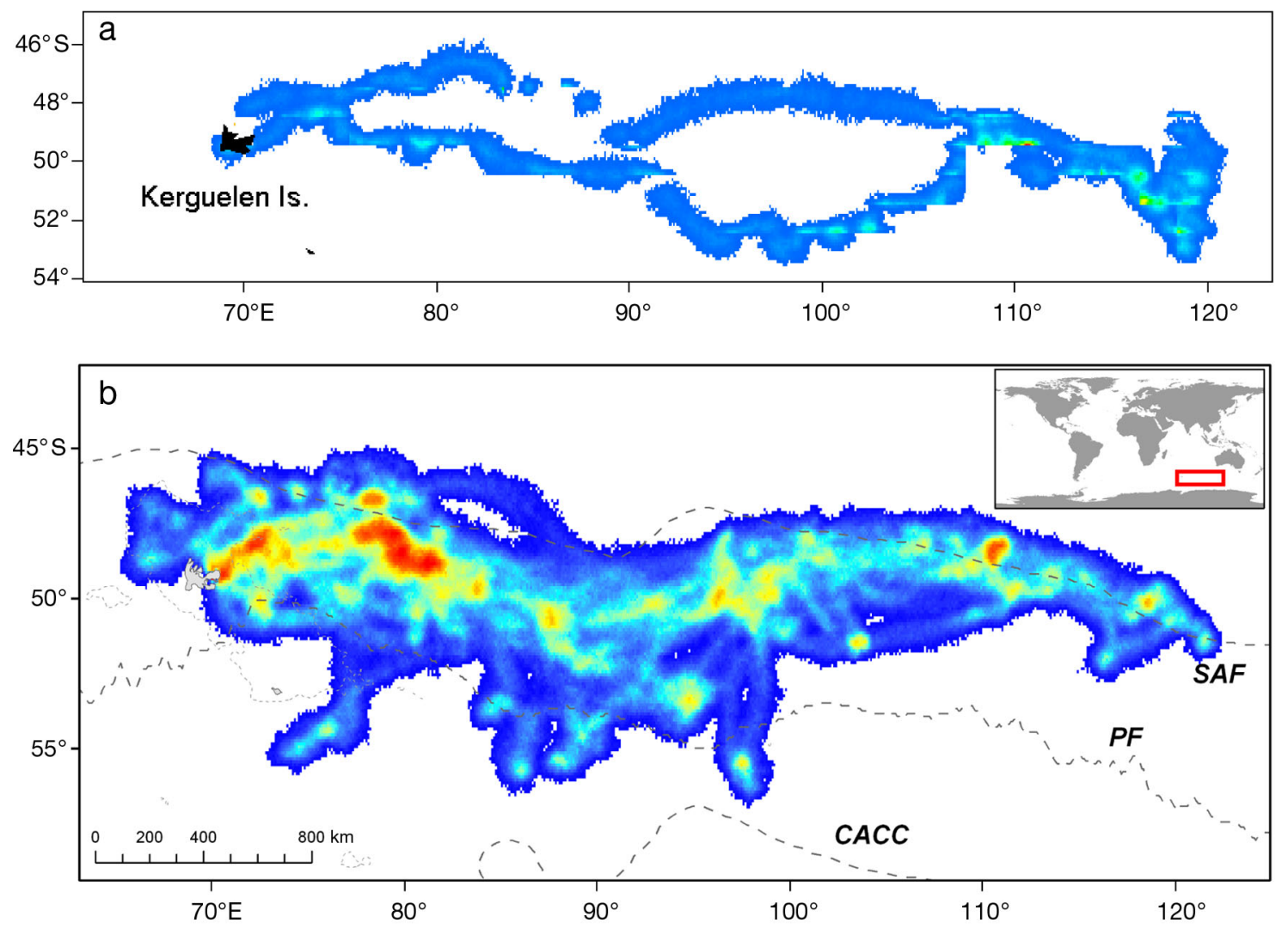

Fig. 4. Eudyptes chrysolophus. Local density of location estimates given by the model for (a) 1 ind. and (b) 12 ind. (from blue: low density, to red: high density), revealing a proxy of habitat use by the individual/population studied. Main oceanographic frontal structures of the southern Indian Ocean are illustrated in (b). Dashed lines show SAF: Sub-Antarctic Front; PF: Polar Front; CACC: conventional southern boundary of the Circum-Antarctic Current

mates from subsequent analyses, unlike with some geolocation software. We therefore feel that we can recommend the use of this approach for optimising the processing of numerous datasets. An important advantage lies in the fact that parameters are based upon objective criteria that refer to the studied species, region and logger, and remain constant for all the individuals processed. The results obtained following this method are thus reproducible and nearly independent of the observer.

\section{Information extracted from the confidence envelope: from individual to population}

A useful outcome of this method is the availability of a posterior distribution of the geolocation estimation, as shown in Figs. 2 \& 3. Our results confirm that the use of a combination of constraints with a probabilistic approach allows the user to determine the spatial likelihood of the estimates (see also Sibert et al. 2003, Nielsen \& Sibert 2007, Lam et al. 2008). The fact that the longitudinal and latitudinal widths of the distributions are similar suggests that the Gaussian assumptions of the Kalman filter (Kalman 1960) lead us to estimate the longitude and latitude of the locations with a comparable likelihood. However, the latitudinal width of the distribution was significantly more variable, and this is doubtlessly related to the sensibility of latitude calculation to equinox periods (see Fig. 2b). Moreover, in a Kalman filter framework, $x$ and $y$ parameters are serially uncorrelated; as a consequence, we observed no correlation between longitude and latitude error estimates.

The production of the posterior distributions is valuable in an ecological investigation of habitat use because it makes it possible to work with the trips at the most appropriate spatial scale, directly integrating the errors. This is especially useful for making correlations with environmental variables. The information gained here about estimated trips shows their strengths as well as their limitations, both of which crucial in spatial analyses. A chief element in this approach is that the posterior distribution was drawn without having to double-tag animals with better reso- 
lution devices, a procedure which would not have been ethically possible in our case (Hull 1997, Wilson et al. 2002, 2004, Bost et al. 2004). Although latitudinal and longitudinal ranges of the posterior distribution cannot be seen as mean errors of geolocation estimations versus satellite-transmitter locations as given by Phillips et al. (2004) on albatrosses, our results are likely to reflect that the probabilistic approach in a template-fitting method can reduce location possibilities, especially with respect to latitude estimates. At the individual level, the local density of estimations by sector (Fig. 4a) may reflect the major wintering grounds used by the animal along its entire winter migration. At a population level, superimposing location estimations given by the model for all individuals (Fig. 4b) therefore makes it possible to infer a proxy of population habitat utilisation during winter, and may highlight migration corridors, if any exist. We propose the use of this local density of location estimation given by the model as an intuitive proxy of probability of habitat use. This proxy may be used as a substitute for the commonly used Kernel density contours homerange method (Worton 1989). Several authors have also proposed modelling methods for estimating home range instead of kernel density contours (e.g. Horne et al. 2007, Dalziel et al. 2008, Pedersen et al. 2008). The method we used to highlight habitat utilisation hotspots is indeed theoretically more appropriate in this case than the Kernel density estimations, as final locations were not observed fixes but the most likely spatial positions regarding the input parameters of the model. No assumption is made in our case to choose the smoothing factor $h$, as the smoothing depends directly on the distribution of the estimation. Hemson et al. (2005) criticised the Kernel method, notably because it gives high failure rates for $n>100$ locations and for intensive use of core areas by the animals. These authors concluded that these biases

...limit the applicability of Kernel density estimates to fewer situations than the literature suggests, and cast doubts over the method's reliability and comparability as a home-range estimator. (p. 455)

This supports our proposal to use the simple intuitive estimator of habitat utilisation to make adapted ecological inference from most likely positions. However, we acknowledge that results of both methods gave very similar patterns with our dataset (see Bost et al. 2009).

Finally, the spatial distribution of location probabilities may be beneficial in habitat modelling. Spatiallyorganised data on habitat parameters such as chlorophyll concentration may be better exploited in a spatially weighted approach, giving adapted importance to each cell in the model according to the local density of locations.

\section{Relevance of the SST-based adjustment}

The dramatic latitudinal difference observed between the 2 parts of the trip obtained with light-only based geolocation (see Figs. 1 \& 3 with highest values of 'ecart' parameter) is presumably due to the opposite directions of the 2 phases in the animal's movement (westward versus eastward). Such longitudinal movement affects day length as recorded by the logger and subsequently latitude estimation (Wilson et al. 1992, Hill 1994). This bias is inherent to light-based geolocation and shows the relevance of an adjustment by SST, particularly in thermally well-structured regions. In the case of fast-moving animals like flying seabirds, the bias is expected to be higher and the need to adjust locations using SST records is emphasised. Unfortunately, the relevance of SST adjustment in this specific case is reduced since SST cannot be recorded so frequently for flying seabirds, and this adjustment will therefore not be applicable over the whole trip.

Larger 'ecart' values provide more latitude possibilities, leading light-based estimation to prevail over SST-based estimation. Conversely, as this value decreases, fewer possible matching latitudes will be found. However, our results show that with a low 'ecart' value, there is an increased probability of obtaining unrealistic latitude variation patterns due to close matching of latitude to SST records, which can be erroneous. Because the logger is closely attached to the bird, heat from the skin or feathers might indeed cause erroneous location adjustment in this cold region. As logger temperature records need to be reliable, loggers should always be tested prior to deployment to ensure their validity or to be able to handle potential bias in temperature recording.

One drawback of the use of SST in this method is that, although SST is slightly higher close to the coast, this was not distinguishable at the spatial scale used. We attribute this to the fact that the trips often appeared to start northward (see Figs. 2 \& 3), so that the higher temperatures found this way would match the records.

This SST-matching procedure was useful in our case, although some bias could not be overcome. To inform potential users of this method about the SST-matching procedure in other cases, we review 5 main limitations and sources of error deriving from the use of SST (see also Teo et al. 2004). First, the template used is generally derived from telemetric data (Teo et al. 2004, Shaffer et al. 2005, Nielsen et al. 2006). Therefore, the area of satellite (or other) coverage may limit the use of such templates. In polar regions, sea ice may strongly limit the availability of telemetric data, and densely clouded regions (e.g. sub-polar and tropical regions) may also lead to limited usefulness of these data. Optimal use of lightbased geolocation remains in temperate regions (Wilson 
et al. 1992, Hill 1994), and in these regions, at least, accurate telemetric-derived templates are usually easy to obtain (Reynolds \& Smith 1994). Second, the temperaturematching procedure is more complicated in the case of deep-diving and non-air-breathing animals, because ambient sea temperature recorded at depth differs from SST. In such cases, the SST-matching procedure will bias a light-based estimation rather than improve it. The only way to improve locations by temperature would be to know the utilisation of the vertical water column by the species and use a temperature template adapted to the most visited layer. This more complicated procedure should be improved by pressure-correction on the temperature records. In our case, we were able to assimilate the ambient temperature readings to the SST, thanks to the diving behaviour of our study model. Third, we were able to make optimal latitudinal correction thanks to the strong latitudinal thermal gradient of the studied region. On a large scale, this latitudinal gradient is present everywhere, and though less pronounced, still allows latitudinal adjustment. However, on a meso-scale, if isotherms are diagonal instead of latitudinal, the longitude estimation has a strong effect on the accuracy of the SST-based latitude estimation (see Teo et al. 2004). In the specific case of locally longitudinal isotherms, the estimation of latitude by SST is insignificant: it should thus be helpful to refine longitude with temperature records. This longitude adjustment combined with a fine land mask could provide improvements in certain specific but intensively studied habitats like coastal upwellings (e.g. Benguela and Humboldt marine systems). Fourth, the use of SST adjustment may become complicated and less relevant in non-linear oceanographic gradient conditions, because several spatial matchings are possible. A major question thus concerns the scale chosen in space and time for the template (see Bradshaw et al. 2002, Galuardi et al. 2008), so as to avoid excessive smoothing wherein fine-scale gradients are merged and SST adjustment is subsequently worthless. Some marine systems are typically structured in strong non-linear gradients (eddies, semi-closed gulfs), and it seems that another information source (such as depth, salinity, magnetic field) should be used in such cases to improve light-based geolocation estimates. Conversely, in quiescent open oceanic regions, high resolution templates should be used to avoid merging fine-scale weak gradients. Finally, in the highest latitude regions (over polar circles), light-based geolocation is not very attractive for tracking animal movements, since over the year, permanent day and night alternate with equinox periods. Improving light-based geolocation estimates by the SSTmatching procedure as presented here (and/or other additional constraints) might be useful to estimate animal movement, particularly over long periods. However, low reliability of temperature records under conditions below $0^{\circ} \mathrm{C}$ is indicated by the manufacturer of the loggers we used. Improvement of this reliability at low temperatures would therefore be valuable to spatially extend the use of light-based geolocation.

\section{CONCLUSIONS}

The method applied here met our goals. Light-based geolocation was performed using the 'TripEstimation' package that included specific behavioural parameters for predicting and correcting autoregressive estimations. The estimations were improved by a facultative SST-matching procedure which produced the most probable locations along entire trips. The strengths of this approach encompass the calculation of realistic locations during equinox periods, while avoiding the time-consuming and subjective step of inspecting the validity of all locations, and the production of a spatial posterior distribution that allows optimal interpretation of habitat use. Finally, the use of a freely available package with extensive free software is also a nonnegligible advantage. This method could be used for any animal group data, although travelling speed, frequency of temperature records and diving behaviour lead us to suggest that SST-improved light-based geolocation is probably better applicable to data obtained from animals of mid- to large size, such as pinnipeds (other than elephant seals), penguins, sea turtles, sea snakes and shallow-diving fishes. Drag effects of the device and its attachment have probably restricted the use of this technique over long periods on mid-sized animals such as penguins in the past, but with logger miniaturisation it should become widespread among researchers working on penguins. Interestingly, Wilson (1995) wrote

Perhaps more than for any other group of birds our knowledge of penguin foraging ecology has been gained as a consequence of technological advances... (p. 81)

This remark is still valuable today, as research for conservation now looks towards tracking animals over extended periods to obtain information on the habitats they depend on during all the periods of their life cycle (Wilson et al. 1998, Weimerskirch \& Wilson 2000, Croxall et al. 2005, Phillips et al. 2006, Shaffer et al. 2006, Bost et al. 2009), promoting the need for still further miniaturisation and improved performance and reliability. Manufacturers are obviously key to such improvements but it is also imperative that methods which improve quality and reliability of the results be developed. The method and R codes presented here should therefore benefit habitat-use ecologists. This method could be especially useful to improve the design of marine protected areas in key habitats of vulnerable predators during critical periods of their life cycle. 
Acknowledgements. This study was financially and logistically supported by the French Polar Institute (Program IPEV 394, directed by C.A. Bost), the National Agency for Research (program ANR Biodiv 07 'GLIDES'), the French Southern Territories administration (TAAF) and UPMC Paris VI University. We thank C.A. Bost for use of his GLS dataset, as well as Y. Charbonnier and S. Mortreux for conducting fieldwork. We are grateful to 2 anonymous referees for their constructive comments, which greatly improved the manuscript, and also to A. Pape and S. Tartu for their help with the English. Our research on a vulnerable animal species was approved by the Ethics Committee of the French Polar Institute and Polar Environment Committee.

\section{LITERATURE CITED}

Bailleul F, Charrassin JB, Ezraty R, Girard-Ardhuin F, McMahon CR, Field IC, Guinet C (2007) Southern elephant seals from Kerguelen Islands confronted by Antarctic sea ice: changes in movements and in diving behaviour. Deep-Sea Res II 54:343-355

Bost CA, Georges JY, Guinet C, Cherel Y and others (1997) Foraging habitat and food intake of satellite-tracked king penguins during the austral summer at Crozet Archipelago. Mar Ecol Prog Ser 150:21-33

Bost CA, Charrassin JB, Clerquin Y, Ropert-Coudert Y, Le Maho Y (2004) Exploitation of distant marginal ice zones by king penguins during winter. Mar Ecol Prog Ser 283:293-297

Bost CA, Thiebot JB, Pinaud D, Cherel Y, Trathan PN (2009) Where do penguins go during the inter-breeding period? Using geolocation to track the winter dispersion of the macaroni penguin. Biol Lett 5:473-476

Bradshaw CJA, Hindell MA, Michael KJ, Sumner MD (2002) The optimal spatial scale for the analysis of elephant seal foraging as determined by geo-location in relation to sea surface temperatures. ICES J Mar Sci 59:770-781

Brillinger DR (1981) Some aspects of modern population mathematics. Can J Stat 9:173-194

Croxall JP, Davis LS (1999) Penguins: paradoxes and patterns. Mar Ornithol 27:1-12

Croxall JP, Silk JRD, Phillips RA, Afanasyev V, Briggs DR (2005) Global circumnavigations: tracking year-round ranges of nonbreeding albatrosses. Science 307:249-250

Culik B, Bannasch R, Wilson RP (1994) External devices on penguins: How important is shape? Mar Biol 118:353-357

> Dalziel BD, Morales JM, Fryxell JM (2008) Fitting probability distributions to animal movement trajectories: using artificial neural networks to link distance, resources, and memory. Am Nat 172:248-258

Delong RL, Stewart BS, Hill RD (1992) Documenting migrations of northern elephant seals using day length. Mar Mamm Sci 8:155-159

Ekstrom P (2007) Error measures for template-fit geolocation based on light. Deep-Sea Res II 54:392-403

> Fauchald P (1999) Foraging in a hierarchical patch system. Am Nat 153:603-613

Fauchald P, Erikstad KE, Skarsfjord H (2000) Scale-dependent predator-prey interactions: the hierarchical spatial distribution of seabirds and prey. Ecology 81:773-783

Field IC, Bradshaw CJA, Burton HR, Sumner MD, Hindell MA (2005) Resource partitioning through oceanic segregation of foraging juvenile southern elephant seals (Mirounga leonina). Oecologia 142:127-135

Fox JW (2009) Geolocator manual v7. British Antarctic Survey, Natural Environment Research Council, Cambridge
Fritz H, Said S, Weimerskirch H (2003) Scale-dependent hierarchical adjustments of movement patterns in a long-range foraging seabird. Proc R Soc Lond B Biol Sci 270: 1143-1148

> Galuardi B, Nielsen A, Lutcavage M (2008) Optimizing smoothed sea surface temperature for improving archival tag geolocation. Mar Ecol Prog Ser 365:35-44

> Geman S, Geman D (1984) Stochastic relaxation, Gibbs distributions and the Bayesian restoration of images. IEEE Trans Pattern Anal Mach Intell PAMI-6:721-741

Gilks WR, Richardson S, Spiegelhalter DJ (1996) Markov Chain Monte Carlo in practice. Chapman \& Hall, London

> Green JA, Boyd IL, Woakes AJ, Warren NL, Butler PJ (2005) Behavioural flexibility during year-round foraging in macaroni penguins. Mar Ecol Prog Ser 296:183-196

Gunn JS, Block BA (2001) Advances in acoustic, archival and satellite tagging of tunas. In: Block BA, Stevens ED (eds) Tunas: ecological physiology and evolution. Academic Press, San Diego, CA, p 167-224

Gunn J, Polacheck T, Davis T, Sherlock M, Betlehem A (1994) The development and use of archival tags for studying the migration, behaviour and physiology of southern bluefin tuna, with an assessment of the potential for transfer of the technology to groundfish research. ICES Mini Symposium on Fish Migration, ICES, Copenhagen, p 1-23

Harvey AC (1989) Forecasting, structural time series models and the Kalman filter. Cambridge University Press, Cambridge

Hastings WK (1970) Monte Carlo sampling methods using Markov chains. Biometrika 57:97-109

Haury LR, McGowan JA, Wiebe PH (1978) Patterns and processes in the time-space scales of plankton distributions. In: Steele JH (ed) Spatial pattern in plankton communities. Plenum Press, New York, NY, p 277-327

> Hays GC (2008) Sea turtles: a review of some key recent discoveries and remaining questions. J Exp Mar Biol Ecol 356:1-7

Hemson G, Johnson P, South A, Kenward R, Ripley R, Macdonald D (2005) Are kernels the mustard? Data from global positioning system (GPS) collars suggests problems for kernel home-range analyses with least-squares crossvalidation. J Anim Ecol 74:455-463

Hill RD (1994) Theory of geolocation by light levels. In: Le Boeuf BJ, Laws RM (eds) Elephant seals: population ecology, behaviour and physiology. University of California Press, Berkeley, CA, p 227-236

Holliday NP, Read JF (1998) Surface oceanic fronts between Africa and Antarctica. Deep-Sea Res I 45:217-238

> Horne JS, Garton EO, Krone SM, Lewis JS (2007) Analyzing animal movements using Brownian bridges. Ecology 88: 2354-2363

Hull CL (1997) The effect of carrying devices on breeding royal penguins. Condor 99:530-534

Hunt GL Jr, Schneider DC (1987) Scale-dependent processes in the physical and biological environment of marine birds. In: Croxall J (ed) Seabirds: feeding biology and role in marine ecosystems. Cambridge University Press, Cambridge, p 7-41

Jonsen ID, Flemming JM, Myers RA (2005) Robust statespace modelling of animal movement data. Ecology 86: $2874-2880$

> Jouventin P, Weimerskirch H (1990) Satellite tracking of wandering albatrosses. Nature 343:746-748

Kalman RE (1960) A new approach to linear filtering and prediction problems. J Basic Eng Trans ASME Ser D 82:35-45

Kotliar NB, Wiens JA (1990) Multiple scales of patchiness and patch structure: a hierarchical framework for the study of heterogeneity. Oikos 59:253-260 
Lam CH, Nielsen A, Sibert JR (2008) Improving light and temperature based geolocation by unscented Kalman filtering. Fish Res 91:15-25

Metropolis N, Rosenbluth AW, Rosenbluth MN, Teller AH, Teller E (1953) Equations of state calculations by fast computing machines. J Chem Phys 21:1087-1091

Musyl MK, Brill RW, Curran DS, Gunn JS and others (2001) Ability of archival tags to provide estimates of geographical position based on light intensity. In: Sibert JR, Nielsen $\mathrm{JL}$ (eds) Electronic tagging and tracking in marine fisheries. Kluwer Academic Publishers, Dordrecht, p 343-367

> Nielsen A, Sibert JR (2007) State-space model for light-based tracking of marine animals. Can J Fish Aquat Sci 64: 1055-1068

Nielsen A, Bigelow KA, Musyl MK, Sibert JR (2006) Improving light-based geolocation by including sea surface temperature. Fish Oceanogr 15:314-325

Park YH, Fuda JL, Durand I, Garabato ACN (2008) Internal tides and vertical mixing over the Kerguelen Plateau. Deep-Sea Res II 55:582-593

Patterson TA, Thomas L, Wilcox C, Ovaskainen O, Matthiopoulos J (2008) State-space models of individual animal movement. Trends Ecol Evol 23:87-94

Pedersen MW, Righton D, Thygesen U, Andersen K, Madsen H (2008) Geolocation of North Sea cod (Gadus morhua) using hidden Markov models and behavioural switching. Can J Fish Aquat Sci 65:2367-2377

Phillips RA, Silk JRD, Croxall JP, Afanasyev V, Briggs DR (2004) Accuracy of geolocation estimates for flying seabirds. Mar Ecol Prog Ser 266:265-272

Phillips RA, Silk JRD, Croxall JP, Afanasyev V (2006) Yearround distribution of white-chinned petrels from South Georgia: relationships with oceanography and fisheries. Biol Conserv 129:336-347

Pickard G, Emery WJ (1990) Descriptive physical oceanography: an introduction. Pergamon Press, Oxford

> Pinaud D, Weimerskirch H (2007) At-sea distribution and scale-dependent foraging behaviour of petrels and albatrosses: a comparative study. J Anim Ecol 76:9-19

Raya Rey A, Trathan PN, Pütz K, Schiavini A (2007) Effect of oceanographic conditions on the winter movements of rockhopper penguins Eudyptes chrysocome chrysocome from Staten Island, Argentina. Mar Ecol Prog Ser 330: 285-295

R Development Core Team (2008) R: a language and environment for statistical computing. R Foundation for statistical computing, Vienna

> Reynolds RW, Smith TM (1994) Improved global sea surface temperature analyses using optimum interpolation. J Clim 7:929-948. http://ingrid.ldgo.columbia.edu/SOURCES/ IGOSS/

Royer F, Fromentin JM, Gaspar P (2005) A state-space model to derive bluefin tuna movement and habitat from archival tags. Oikos 109:473-484

Sato K, Watanuki Y, Takahashi A, Miller PJO and others (2007) Stroke frequency, but not swimming speed, is related to body size in free-ranging seabirds, pinnipeds and cetaceans. Proc R Soc Lond B Biol Sci 274:471-477

Shaffer SA, Tremblay Y, Awkerman JA, Henry RW and others (2005) Comparison of light- and SST-based geolocation with satellite telemetry in free-ranging albatrosses. Mar Biol 147:833-843

Shaffer SA, Tremblay Y, Weimerskirch H, Scott D and others (2006) Migratory shearwaters integrate oceanic resources

Editorial responsibility: Rory Wilson,

Swansea, UK across the Pacific Ocean in an endless summer. Proc Natl Acad Sci USA 103:12799-12802

Sibert JR, Fournier DA (2001) Possible models for combining tracking data with conventional tagging data. In: Sibert JR, Nielsen JL (eds) Electronic tagging and tracking in marine fisheries reviews: methods and technologies in fish biology and fisheries. Kluwer Academic Press, Dordrecht, p 443-456

Sibert JR, Musyl MK, Brill RW (2003) Horizontal movements of bigeye tuna (Thunnus obesus) near Hawaii determined by Kalman filter analysis of archival tagging data. Fish Oceanogr 12:141-151

Smith P, Goodman D (1986) Determining fish movements from an 'archival' tag: precision of geographical positions made from a time series of swimming temperature and depth. NOAA Tech Memo NMFS SWFC 60: 1-13

Steele JH (1976) Patchiness. In: Cushing DH, Walsh JJ (eds) The ecology of the seas. Blackwell Scientific Publications, Oxford, p 98-115

Steele JH (1989) The ocean 'landscape'. Landscape Ecol 3:185-192

Sumner MD, Wotherspoon SJ, Hindell MA (2009) Bayesian estimation of animal movement from archival and satellite tags. Plos One 4:e7324

Swart NC, Ansorge IJ, Lutjeharms JRE (2008) Detailed characterization of a cold Antarctic eddy. J Geophys Res C 113:C01009

> Takahashi A, Sato K, Naito Y, Dunn MJ, Trathan PN, Croxall JP (2004) Penguin-mounted cameras glimpse underwater group behaviour. Proc R Soc Lond B Biol Sci 271: S281-S282

Teo SLH, Boustany A, Blackwell S, Walli A, Weng KC, Block BA (2004) Validation of geolocation estimates based on light level and sea surface temperature from electronic tags. Mar Ecol Prog Ser 283:81-98

> Véran S, Lebreton JD (2008) The potential of integrated modelling in conservation biology: a case study of the black-footed albatross (Phoebastria nigripes). Can J Stat 36:85-98

Weimerskirch H, Wilson RP (2000) Oceanic respite for wandering albatrosses. Nature 406:955-956

Wilson RP (1995) Foraging ecology. In: Perrins CM, Bock WJ, Kikkawa J (eds) The penguins. Oxford University Press, Oxford, p 81-106

Wilson RP, Ducamp JJ, Rees G, Culik BM, Niekamp K (1992) Estimation of location: global coverage using light intensity. In: Priede IM, Swift SM (eds) Wildlife telemetry: remote monitoring and tracking of animals. Ellis Howard, Chichester, p 131-134

- Wilson RP, Alvarrez B, Latorre L, Adelung D, Culik B, Bannasch R (1998) The movements of gentoo penguins Pygoscelis papua from Ardley Island, Antarctica. Polar Biol 19:407-413

Wilson RP, Gremillet D, Syder J, Kierspel MAM and others (2002) Remote-sensing systems and seabirds: their use, abuse and potential for measuring marine environmental variables. Mar Ecol Prog Ser 228:241-261

Wilson RP, Kreye JA, Lucke K, Urquhart H (2004) Antennae on transmitters on penguins: balancing energy budgets on the high wire. J Exp Biol 207:2649-2662

Wilson SG, Stewart BS, Polovina JJ, Meekan MG, Stevens JD, Galuardi B (2007) Accuracy and precision of archival tag data: a multiple-tagging study conducted on a whale shark, Rhincodon typus, in the Indian Ocean. Fish Oceanogr 16:547-554

Worton BJ (1989) Kernel methods for estimating the utilization distribution in home-range studies. Ecology 70: 164-168

Submitted: April 3, 2009; Accepted: November 29, 2009

Proofs received from author(s): January 27, 2010 